\title{
Contextualization of Traditional Physical Activity "Ekienga" in Physical Education at Congolese Primary School
}

\author{
Lembe Gorgon (Corresponding author) \\ Laboratory of Didactics of Physical Education \\ Higher Institute of Physical Education and Sports \\ Marien Ngouabi University, Brazzaville, Congo \\ Tel: 242-06-654-9424 E-mail: drgorgonlembe@gmail.com
}

\begin{abstract}
Mviri Hubert César
Laboratory of Didactics of Physical Education

Higher Institute of Physical Education and Sports

Marien Ngouabi University, Brazzaville, Congo

E-mail: husarm@gmail.com
\end{abstract}

\begin{abstract}
Entsiro François
Laboratory of Didactics of Physical Education

Higher Institute of Physical Education and Sports

Marien Ngouabi University, Brazzaville, Congo

E-mail: kiatali2008@gmail.com
\end{abstract}

Ewamela Aristide

Laboratory of Didactics of Physical Education

Higher Institute of Physical Education and Sports

Marien Ngouabi University, Brazzaville, Congo

E-mail: bearistide2099@gmail.com 
Massamba Alphonse

Laboratory of Sports Biosciences, Biomechanics and Movement Analysis

Higher Institute of Physical Education and Sports

Marien Ngouabi University, Brazzaville, Congo

E-mail: mboya53@gmail.com

Received: February 11, 2020 Accepted: March 13, 2020 Published: March 25, 2020

doi:10.5296/jei.v6i1.16346 URL: https://doi.org/10.5296/jei.v6il.16346

\begin{abstract}
The aim of the study was to identify and analyze the motor behaviors of practitioners of the traditional Congolese Ekienga activity, and to offer teaching content for this activity at primary school level in the context of physical education. The research, observational and didactic, was based on the one hand on the evaluation of the bodily gestures carried out during Ekienga in 34 adult men, and on the other hand the construction of teaching programs. The results obtained showed that Ekienga's internal logic allows the construction of knowledge and relevant teaching content in physical education at primary school in Congo.
\end{abstract}

Keywords: Traditional physical activity, Ekienga, Knowledge, Teaching content, Physical education

\title{
1. Introduction
}

The school aims to achieve the objectives intended for the complete development of the child through so-called teaching disciplines including physical education. Indeed, physical education help children to learn and develop transversal skills (Pineau, 1990). It integrates the bodily dimension (Caumel, 1995) and improves specific skills in the personal field of physical activities and sports (Famose, 2002). For this, Physical Education uses Physical and Artistic Activities and Sports as teaching means. Among these, we find more and more nowadays the Traditional Physical Activities (TPA), in accordance with the recommendations of UNESCO (2005). Indeed, during the $32^{\text {nd }}$ conference in Paris, this United Nations institution demonstrated to safeguard traditional physical activities. For this, it proposed an edition of the world encyclopedia of traditional physical activities, recommending that each member state identify and inventory the traditional physical activities specific to each country. These inventories should be updated regularly. Furthermore, at the end of this conference, it was mentioned in its article 13 among other measures "to encourage scientific, technical and artistic studies as well as research methodologies for an effective safeguarding of the immaterial cultural heritage in danger. ". Despite the possibilities offered by traditional physical activities in the development of different socio-motor and psychomotor skills (Chevalier, 2004; Lembé, 2012), educational 
practices in the Congo attach little importance to the development of traditional physical activities in schools. In this context, it is that we conducted a study on "The Integration of Traditional Physical Activities in Primary School: Decontextualization and contextualization" (Lembe, 2009). The author has counted 10 major traditional physical activities: (1) Bulged (jump from a doubled rope and seized at its ends by two partners, (2) Lipato li tsé (chase with possibility of hiding), (3) Likakou (game which consists in mimicking the gestures of a monkey), (4) Mandzandza-mandzandza (dance game which consists in crossing the feet, while holding ropes by the heels making them describe the figures in 8), (5) Zero mupedale (crossing of legs between two strings in two stages), (6) Enguendo Modzika (gathering of nuts in the dry or flooded forest without interruption respecting the mode of locomotion), (7) Lipondza (set of arrows on a spongy target with a liana bow), (8) Mfongo (traditional combat which is accompanied by song whose two partners surround the area behind the lumbar area of the opponent; as soon as one of they or both realize that the grip is perfect, each ten you to lift the other one and throw it on the ground), (9) Ndzango (traditional artistic game which consists of jumping and taking out the gaining foot, previously chosen for convenience), and (10) Ekienga which is the subject of our present study. This study, which made it possible to show the existence of internal logics within the following Congolese TPAs: Ekienga, Mfongo and Ndzango, focused on the decontextualization of these APTs with a view to their integration into the teaching of physical education at the Congolese primary school. In the pursuit of this research, we recently looked at the contribution of the TPA Ekienga in the acquisition of knowledge in physical education in primary school (Lembe, Ewamela, \& Massamba, 2019). The authors have shown that Ekienga's teaching content enables significant improvement in motor skills and functioning skills of the learner group. These observations are in line with the recommendations of UNSECO on the contribution of traditional games to the community identity of individuals (UNESCO, 2005).

\section{Method}

\subsection{Aim}

The aim of this study is to recontextualize Ekienga by developing specific teaching content by observing the sequences of Ekienga practices and confirming the internal logic of the activity.

\subsection{Research Hypotheses}

The study hypotheses can be formulated as follows: if Ekienga is practiced according to the existing internal logic, its decontextualization can allow its integration into the teaching of physical education in primary school.

\subsection{The Participants}

The study was carried out in Brazzaville, political and administrative capital of the Republic of Congo, from February 1 to May 18, 2019. The grouping of people of all ethnicities from the Congo to Brazzaville explains the choice of this city, added to the presence of certain groups of Ekienga practitioners. This study included people from the northern Departments of the Republic of Congo. However, only Ekienga practitioners from these departments and 


\section{Ml Macrothink}

present in Brazzaville included in our research population. A sample was taken from this population, taking into account the number of people who actively participated as actors. It consisted of 34 men (mean age: $34.3 \pm 2.7$ years; range: $31-43$ years), sample size chosen for convenience. They were all from the West Cuvette Department (one of the departments of northern Congo) where Ekienga has its origins. This traditional activity is practiced in the Congolese forest basin as part of the preparation of young people for hunting. It is thus found in rural festivities under two names according to the ethnic group, "Bongolo" or "Gnari". A cylinder and a lance are used in the village courtyard in order to reach and immobilize the moving cylinder by the lance jet at optimal speed. This practice contributes to the development of skills: reaction speed, tension, strength, etc. The instruments used are: wooden spears ( 3 meters long and relatively light), cylinders made from banana or wood root (spongy) $(11 \mathrm{~cm}$ in radius), a ground or flat space of at least $(40 \times 40$ meters), and ten subjects per team.

Ekienga is practiced with the opposition of two groups with equal numbers. In our study, the men in group 1 are made up of cylinder rollers, those in group 2 are hunters. During this practice, a member of group 1 rolls the cylinder and each hunter group 2 launches the lance when passing the cylinder to its level in order to reach it, fix it and immobilize it. After the roll by the first pitcher in group 1, the men in group 2 in turn roll the cylinder and those in group 1 throw the lance on the cylinder and so on. The appreciation of the gain of a point is based on the fixing of the cylinder with immobilization. After scoring points, the game is won by the group that wins the most points compared to the other. However, the team that manages to roll the cylinder well under the regulatory conditions (in a straight line and at full speed) without any member of the opposing team reaching it and immobilizing it also gains one point. However, it is prohibited for subjects during the game to: pick up the lance when the cylinder is in motion; throw the lance when the cylinder is not your author.

The two groups of students are placed alternately to the right of the launcher, as illustrated in Figure 1.

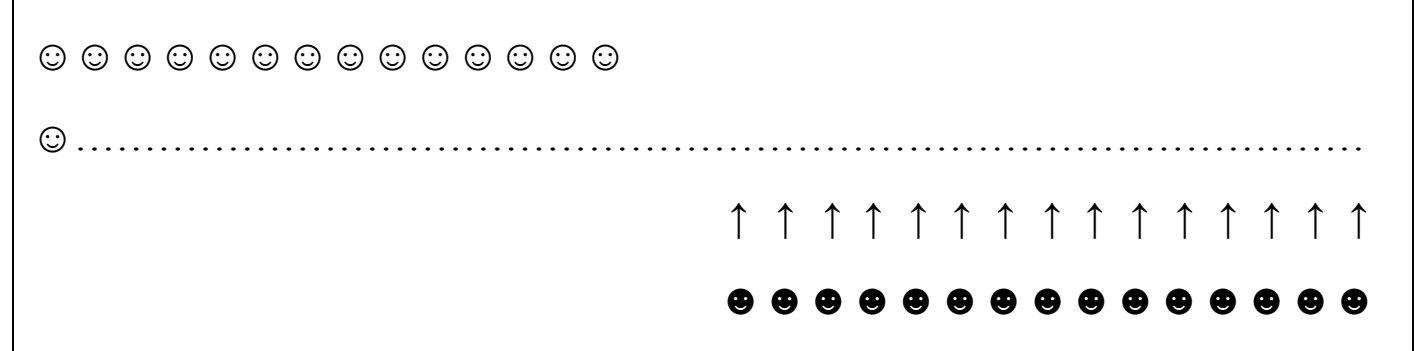

Figure 1. Ekienga device 


\section{1) Macrothink}

\subsection{Research Tools}

The survey consisted first of all in filming (semi-direct observation) Ekienga's practices in the adult subjects mentioned above. The films were produced using a SONY 800PX brand camera.

Subsequently, based on the internal logic of Ekienga, teaching content was developed in order to contextualize the practice of Ekienga among Congolese schoolchildren during physical education.

\section{Findings}

\subsection{Observation of Ekienga}

Ekienga's decryption made it possible to observe: the driving behaviors of the cylinder rollers and the shape of the cylinder trajectory; the engine behavior of the arrow launchers and the performance achieved.

\subsubsection{Engine Behavior of Cylinder Rollers}

Table 1 shows the numbers and percentages of cylinder launchers according to the adoption of anteroposterior and lateral supports when rolling the cylinder.

Table 1. Distribution of cylinder launchers according to the type of support adopted (anteroposterior vs lateral deviations) during rolling

\begin{tabular}{|l|l|l|l|}
\hline & $\mathrm{n}$ & $\%$ & $\mathrm{p}$ \\
\cline { 1 - 3 } Anteroposterior gap support & 32 & $92.1^{* * *}$ & \multirow{2}{*}{$<0.001$} \\
\cline { 1 - 4 } Support in lateral deviation & 2 & 5.9 & \\
\cline { 1 - 4 } Total & 34 & 100 & \\
\hline
\end{tabular}

Note. ${ }^{* * *}: \mathrm{p}<0.001$.

Analysis of the data in Table 1 shows that $92.1 \%(\mathrm{p}<0.001)$ of cylinder rollers have adopted anteroposterior support, compared with $5.9 \%$ in lateral deviation.

With regard to the synchronization of the members of the rollers, an absolute synchronization of the members of the rollers of the cylinder has been observed.

\subsubsection{Cylinder Trajectory}

Table 2 shows the distribution of cylinder rollers according to the trajectory described by the rotating cylinder. 


\section{Macrothink}

Table 2. Distribution of cylinder rollers according to the trajectory (rectilinear vs curvilinear) by the rotating cylinder describe

\begin{tabular}{|l|l|l|l|}
\hline & $\mathrm{n}$ & $\%$ & $\mathrm{P}$ \\
\hline Straight path & 22 & 65 & \multirow{2}{*}{ NS } \\
\hline Curvilinear trajectory & 12 & 35 & \\
\hline Total & 34 & 100 & \\
\hline
\end{tabular}

Note. NS: No significant difference.

Analysis of the data in Table 2 reveals that during Ekienga's practice, no significant difference was found between the rollers whose cylinder trajectories were either straight or curvilinear.

\subsubsection{Engine Behavior of Lance Launchers}

The distribution of launchers according to the option of anteroposterior and lateral deviation supports is shown in Table 3.

Table 3. Distribution of launchers according to anteroposterior and lateral deviation supports

\begin{tabular}{|l|l|l|l|}
\hline & $\mathrm{n}$ & $\%$ & $\mathrm{p}$ \\
\hline Anteroposterior gap support & 31 & $91.2^{* * *}$ & \multirow{2}{*}{$<0.001$} \\
\hline Lateral support & 3 & 8.8 & \\
\hline Total & 34 & 100 & \\
\hline
\end{tabular}

Note. ${ }^{* * *}: \mathrm{p}<0.001$.

It appears that the launchers placed their supports more in anteroposterior distance $(91.1 \%)$ than in lateral deviation $8.8 \%$, the difference being significant $(\mathrm{p}<0.001)$.

The numbers (n) and percentages (\%) of launchers according to the adoption of an armed or flexed arm during the launch are reported in Table 4. 


\section{Macrothink}

Table 4. Distribution of subjects according to the armed arm and the bent arm

\begin{tabular}{|l|l|l|l|}
\hline & $\mathrm{n}$ & $\%$ & $\mathrm{P}$ \\
\hline Armed arm & 30 & $86.9 * * *$ & \multirow{2}{*}{$<0.001$} \\
\cline { 1 - 3 } Bent arm & 4 & 13.1 & \\
\hline Total & 34 & 100 & \\
\hline
\end{tabular}

Note. ${ }^{* * *}: \mathrm{p}<0.001$

In total, the launchers adopted the posture of the armed arms more $(869 \% ; p<0.001)$ than that of the bent arms, during the execution of the throw.

Table 5 reports the numbers (n) and percentages (\%) of launchers in relation to the level of non-fixation, fixation without immobilization and fixation with immobilization.

Table 5. Distribution of launchers in relation to non-fixing of the cylinder, fixing without immobilization and fixing with immobilizing the cylinder

\begin{tabular}{|l|l|l|l|}
\hline & $\mathrm{n}$ & $\%$ & $\mathrm{P}$ \\
\cline { 1 - 2 } Non fixation du cylindre & 22 & 64.7 & \multirow{2}{*}{ NS } \\
\cline { 1 - 3 } Fixation sans immobilisation du cylindre & 1 & 3.0 & \\
\cline { 1 - 3 } Fixation avec immobilisation du cylindre & 11 & 32.3 & \\
\cline { 1 - 3 } Total & 34 & 100 & \\
\hline
\end{tabular}

Note. NS: No significant difference.

No significant difference existed between the number of launchers compared to the non-fixing of the cylinder, the fixing of the cylinder without immobilization and the fixing with immobilization of the cylinder. 


\subsection{Decontextualization of Ekienga in Primary School}

\subsubsection{Device}

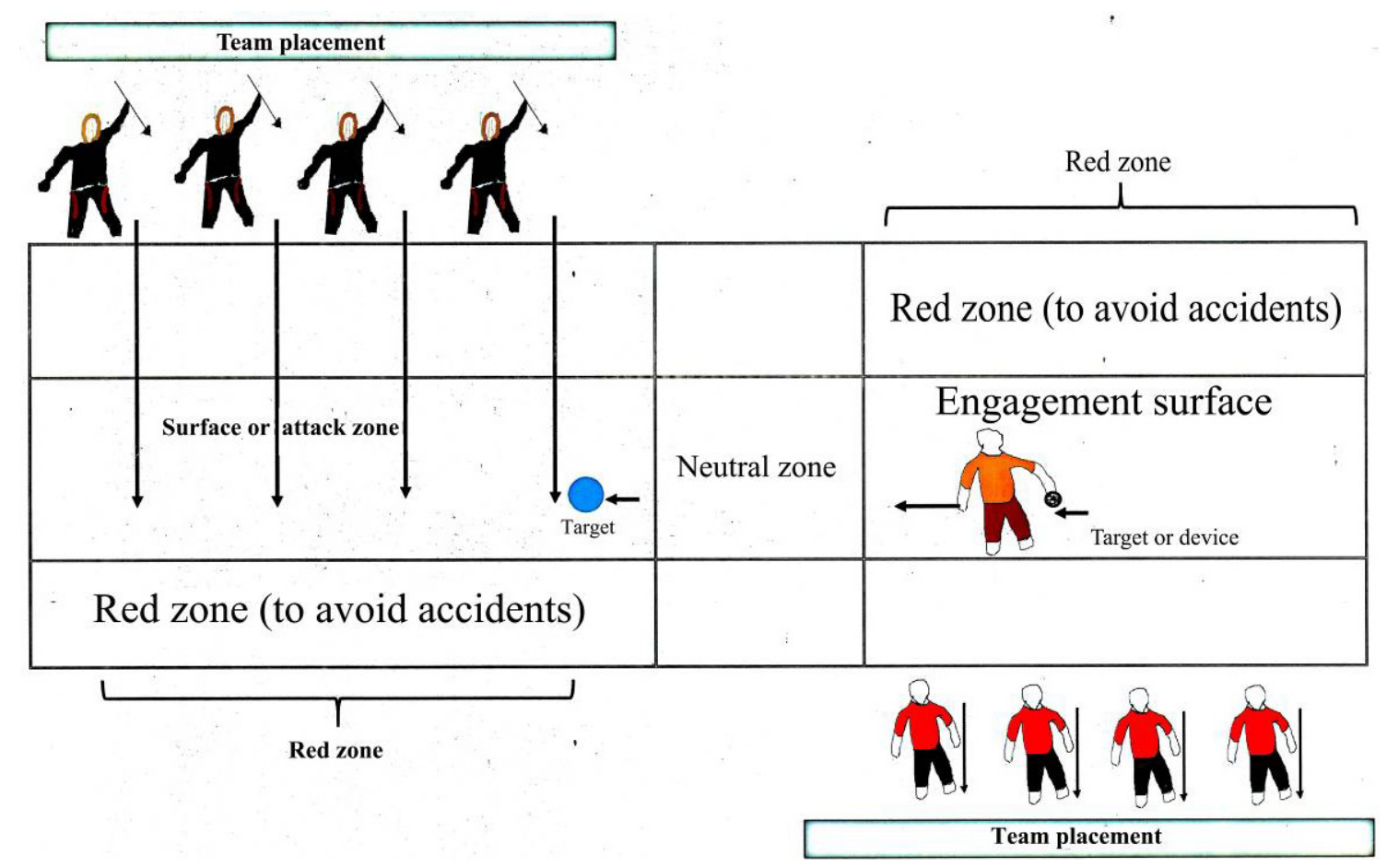

Figure 2. Diagram of the contextualized Ekienga floor

\subsubsection{Teaching Content}

(1) Preparatory Course First Year

General objective: Explore different forms of manipulation.

\begin{tabular}{|l|l|}
\hline Specific objective & $\underline{\text { Notional content }}$ \\
\hline Launch an object & Throw spears at a cylinder motionless \\
\hline
\end{tabular}

(2) Preparatory Course Second Year

General objective: To develop handling and opposition skills.

\begin{tabular}{|l|l|}
\hline Specific objective & Notional content \\
\hline Handling an object & $\begin{array}{l}\text { - Cylinder grip with two hands } \\
\text { - Bearing of a cylinder with twomains }\end{array}$ \\
\hline Launch an object & $\begin{array}{l}\text { Launch of the lance without an impulse on a } \\
\text { mobile cylinder in the form of translation }\end{array}$ \\
\hline
\end{tabular}


(3) First Year Elementary Course

General objective: Develop different forms of locomotion and manipulation.

\begin{tabular}{|l|l|}
\hline Specific objective & Notional content \\
\hline Launch an object & Launching a lance on a cylinder mobile after a walk \\
\hline
\end{tabular}

(4) Elementary Course Second Year

General objective: Develop the different forms of locomotion and manipulation skills specific to athletics.

\begin{tabular}{|l|l|}
\hline Specific objective & $\underline{\text { Notional content }}$ \\
\hline \multirow{3}{*}{ Improve your physical qualities } & - Taking the cylinder with two hands \\
& - Rolling the cylinder with one hand \\
& - Launch the lance on the cylinder after a race \\
\hline
\end{tabular}

(5) Average Course First Year

General objective: To develop the skills of locomotion and manipulation specific to athletics.

\begin{tabular}{|l|l|}
\hline Specific objective & Notional content \\
\hline \multirow{3}{*}{ Improve your throw } & - Improved throws: \\
& . Grip of the lance \\
& . Momentum: race \\
& - Execution of the throw on a cylinder \\
& - Mobile \\
\hline
\end{tabular}

(6) Second Year Average Course

General objective: To develop the skills of locomotion and manipulation specific to athletics

\begin{tabular}{|l|l|}
\hline$\underline{\text { Specific objective }}$ & $\underline{\text { Notional content }}$ \\
\hline \multirow{4}{*}{ Improve your motor actions } & - Improvement of motor actions at the lance launch: \\
& $\begin{array}{l}\text { - Lance grip } \\
\text { - Race and lance launch on a cylinder } \\
\text { - Chain: grip of the lance, run-up and throw } \\
\text { of the lance on a mobile cylinder }\end{array}$ \\
\hline
\end{tabular}

3.2.3 Didactic Frame of Ekienga

(1) Learning Lesson $n^{\circ} 1$

\section{Terminal operational objective}




\section{Macrothink}

At the end of the lesson, the student must be able to roll a cylinder in a straight line, and launch on a mobile cylinder at least 5 times in 15 minutes under the regulatory conditions.

\section{Learning situations}

Students line up in two teams;

Hold the cylinder with two hands, one foot (right) forward;

The first team rolls the cylinder on the ground with force towards the second team, placed aside.

\section{Evaluation criteria}

Students are lined up in batches at regular intervals of at least 1 meter.

The students have their elbows forward, the lance on their heads and the lance tilted slightly upwards.

The rollers of the cylinder first have lateral spreading legs.

The rollers of the cylinder then have their legs in anteroposterior distance.

The rollers hold the cylinder with both hands.

(2) Learning Lesson $n^{\circ} 2$

\section{Terminal operational objective}

At the end of the lesson, the student must be able to throw a lance 5 times in 15 minutes on a mobile cylinder after a dash in the regulatory conditions.

\section{Learning situation}

The pupils are placed on lines previously drawn on the ground.

The group of rollers is placed 10 meters from the group of launchers and rolls the cylinder; each student in the throwing group is in a corridor at least 1.25 meters wide.

Hold the arrow with one hand in the direction of the cylinder, bend forward, look at the cylinder and launch into the path.

\section{Evaluation criteria}

Students are lined up in batches at regular intervals of at least 1 meter.

Each student respects their lane.

The student holds the spear, thumb to the back of the spear, semi bent arm.

The pupil has his legs in antero posterior distance.

\section{(3) Learning Lesson $\mathbf{n}^{\circ} \mathbf{3}$}

\section{Terminal operational objective}




\section{Macrothink}

At the end of the lesson, the student must be able to roll a cylinder 5 times in ten passes with an effective cylinder quoted in the regulatory conditions.

\section{Learning situations}

Students of the roller team placed 1 meter from the line.

Pupils on the other side are waiting for the rolling cylinder.

Be in a semi-flexed position.

Hold the object (cylinder) with two hands:

- palm of the left hand above the cylinder, that of the right hand below;

- arms stretched with the cylinder back;

- advanced left leg (for right-handers);

- advanced right leg (for left-handers).

\section{Evaluation criteria}

Launcher launchers: launcher arm extended at launch

Rollers: two arms stretched at the time of rolling, cylinder held back and forth with a supporting hand and a supporting hand.

(4) Learning Lesson $n^{\circ} 4$

\section{Terminal operational objective}

At the end of the lesson, the student must be able to throw the lance three times on the cylinder (reach) after a fast walk under the regulatory conditions in 5 shots.

\section{Learning situations}

The students of the throwing team are 1 meter from the throwing line;

They make throws during the course of the cylinder after a fast walk;

Hold the cylinder with two hands;

Staring forward.

\section{Evaluation criteria}

The arrow thrower gradually reaches the arm while walking until you get a wide angle (having your arm extended) when launching

(5) Learning Lesson $n^{\circ} 5$

\section{Terminal operational objective}

At the end of the lesson, the student should be able to launch by adjusting the step to cylinder speed three times out of 5 in 10 minutes. 


\section{Macrothink}

\section{Learning situations}

The lance launchers are placed 1 meter from the line of the throw;

Hold the lance with one hand;

Gain momentum by walking to launch from the execution line, when the cylinder passes in front of its lane.

\section{Evaluation criteria}

Outstretched arms;

Appreciate the speed of the cylinder.

(6) Learning Lesson $n^{\circ} 6$

\section{Terminal operational objective}

At the end of the lesson, the student must be able to roll and target the cylinder under regulatory conditions three times out of 5 in 10 minutes while immobilizing the cylinder.

\section{Learning situations}

Students keep the same teams;

Team A rolls the cylinder, uses force to give it maximum speed;

Team B launches on the cylinder as it passes each respective lane.

\section{Evaluation criteria}

Cylinder at full speed;

Reach the cylinder by the arrow.

(7) Learning Lesson $n^{\circ} 7$

\section{Terminal operational objective}

At the end of the lesson, the student must be able to coordinate the throwing of the cylinder and the throwing of the lance under regulatory conditions three times out of 5 in 10 minutes while immobilizing the cylinder.

\section{Learning situations}

Students keep the same teams;

The rollers are placed on a transverse line of the field while the throwers are on the waiting line located 3 meters from the execution line;

Team A rolls the cylinder forward;

Team B throws on the cylinder 


\section{Macrothink}

\section{Evaluation criteria}

Progressive stroke, immobilize the cylinder by the lance.

Cylinder at full speed, cylinder in a straight line

(8) Learning Lesson $n^{\circ} 8$

\section{Terminal operational objective}

At the end of the lesson, the student must be able to express their skills freely under the regulatory conditions 5 times out of 5 in 10 minutes while immobilizing the cylinder.

\section{Learning situations}

Students practice technical and tactical skills.

Students express themselves freely.

\section{Evaluation criteria}

Immobilize the cylinder.

Terminal lesson

At the end of the lesson, the student must be able to present their knowledge in the regulatory conditions.

\section{Learning objective and situations}

The objective and the learning situations are similar to those of the introductory lesson.

\section{Evaluation criteria}

Immobilize the cylinder of each bearing each time it is launched.

\section{Discussion}

The data from this work provide a model of developmental and educational study through traditional physical activities in physical education on tonic-postural training and its effects on the relational behaviors of the learner (Fernandez, 2002; Sackett, 1991), the expression of emotions (Christophel, 1990), the installation and development of capacity to imitate motor gestures (Hinshow, 1983), subject-model interactions in the imitation-restitution process (Paivo, 1985), but also a function of imitation as a means of acquisition and a mode of relationship (Barbry, 1999). The results of the decryption of the Ekienga images indicate that the placement of the cylinder rollers in anteroposterior deviation is significantly greater compared to the placement in lateral deviation $(94.12 \%$ vs $5.88 \% ; \mathrm{p}<0.001$, Table 1$)$. The adoption of this attitude is dependent on the nature of the movement in carrying out the task of rolling the cylinder. Indeed, the movement in translation allows after taking the cylinder in retro pulse to achieve a propulsive antepulsion. Indeed, placement in anteroposterior gap is more favorable in translational movements. For example, it no longer has to be shown that when javelin is thrown, the launcher must make his skipping start in anteroposterior 
separation in order not to interrupt or disrupt the launch path and thereby reduce the effectiveness of propulsion. Bowling in its swing phase requires placing the supports in an anteroposterior gap in order to better orient the center of gravity and in the throw, this gap becomes more marked allowing the player to project his arm forward to release the ball (Fortin, 2000).

The placement in anteroposterior distance of the rollers of the cylinder determines the synchronization of the members of the rollers and the type of trajectory of the cylinder. The results obtained show an absolute synchronization of the members during the rolling of the cylinder ( $\mathrm{n}=34$, i.e., $100 \%$; Table 2$)$. The synchronization of the limbs is linked to the ability of the rollers to perform their movement with flexibility, precision and without significant energy expenditure, thus reflecting good motor coordination.

However, no significant difference appears in the rectilinear and curvilinear trajectories described by the cylinder. An explanatory factor would be the imperfection of the terminal phase of the rotation, no doubt due to the non-fixation of the shoulders and the imbalance movement of the pedestrian supports. Indeed, the non-fixation of the shoulders affects the trajectory of the propelled vehicle. In throws, the non-fixation of the shoulders drives the machine out of the fall sector (Fortin, op.cit.). In addition, the imbalance movements of the pedestrian supports during the propulsion phase disturb the body and control of the craft. In fact, in the event of an imbalance, the torsional bust during the retro-drive is faced with difficulties during the passage of the anti-drive; as a result, the craft can no longer be properly controlled and propelled. It is generally accepted that during the last two presses, the feet are anchored to the ground almost simultaneously and the maximum concentration relates to the most dynamic throw possible (Fortin, op. cit.).

Consequently, the subject who targets the cylinder with spears, which is assimilated to the hunter, determines the stake of the TPA Ekienga. The effectiveness of its throw is linked to the nature of the support gap and the placement of the arm holding the lance. The results that we have achieved indicate that our launchers indifferently place their anteroposterior gap and lateral gap. This attitude undoubtedly reflects the lack of structuring of the lessons and no respect for the principles of training. In fact, our subjects did not train regularly and the training did not follow a well-developed program. They happened to be just for free Ekienga practice. The no-structuring of the lessons and the no-respect of the principles of the training therefore do not make it possible to deduce the motor responses which did not allow the practitioners to acquire by hand the ability to give the last impulse.

Our data also showed that the launchers placed their spears more with the armed arm compared to the bent arm $(91.18 \%$ vs $8.82 \% ; \mathrm{p}<0.001$, Table 3$)$. The adoption of the armed arms by launchers can be explained by the search for motor efficiency, notably the search for strength and speed of execution. Indeed, the cylinder being a moving target, the launcher must act quickly and with force. The speed of execution is then necessary for the inflection of the trajectory of the arrow on the cylinder, therefore for a complex ballistic adjustment. In addition, the force allows the lance in contact with the cylinder to attach to it to reduce its stroke and above all to immobilize it. Another explanatory factor of the armed arms is linked 
to the advisability of this position of the launching arm on the launch path and hence the effectiveness of the throw. It has been reported in this connection that launching is all the more effective as the launching path is very important, with the consequence that launching is more efficient in fixing and immobilizing the cylinder.

It was also noted that the percentages of launchers did not differ in terms of non-fixation, fixation without immobilization and fixation with immobilization of the cylinder (Table 5). This observation can be attributed not only to a poor appreciation of the trajectory and speed of the cylinder, but also to the instability of progression of the ground support. This poor appreciation of the trajectory and of the speed of progression of the cylinder are linked to a bad treatment of the information of environmental origin, the information is received, stored, processed and selected in the memory for a motor production (Famose, 2002). According to this author, taking into account the elements of the environment induces better occulo-spatial coordination; this is part of two approaches to motor learning, cognitive psychology approach and ecological approach.

It is in this context that we proposed by level of study the general objectives, the specific objectives, the notional contents and the criteria of evaluation of lessons of TPA Ekienga during physical education. This didactic path makes it possible to orient work towards the student's main activity, taking into account their level of education and their age. In this regard, Chevalier (2004) indicated that human organization in the teaching-learning process must take into account the age and educational level of the learner. The National Institute for Research and Educational Action (INRAP, 2003), an organ of the Congolese Ministry of National Education, has published a program book developed according to the pupils' educational levels. In our study, Ekienga's teaching in physical education was designed at the first year preparatory level, to achieve the following general objective: to explore different forms of manipulation. This objective is linked to the discovery and the beginning of the use of objects by neophyte pupils in the whole of a structured and controlled activity which is that of the lesson. Indeed, the children of the Congolese primary school having largely not benefited from a preschool education, are faced with a new situation of school life marked by the discovery, the work guided by the teacher, the evaluation constraints...

To achieve this general objective, the specific objective has been defined as follows: to launch an object. Furthermore, the notional content is the jet of the lance on a stationary cylinder. The jet of the lance on a stationary cylinder is explained by the first phase of manipulation activity whose psychomotor skill to develop is the skill. Indeed, it is necessary for a neophyte student to start the static activity before moving on to a dynamic activity. The static action allows the child to better perceive the target, to make a momentum and a throw with little difficulty. This can be understood by the fact that the best capture, the best processing and the best selection of information are necessary to act with precision and without a significant energy expenditure. This action is much more adequate when the elements of the environment are taken into account. According to Famose (2002), perception in the processing of information and its selection are determining factors in occulospatial coordination and reduce errors during the performance of motor tasks. 
With regard to the students in the second year preparatory course, we proposed learning the TPA Ekienga in physical education in order to achieve the following general objective: to develop handling and opposition skills. In this general objective, in addition to handling skills, there are those of opposition. The opposition is linked to the confrontation and generates more work compared to the previous level. This reinforces the hypothesis of the development of curriculum content according to the level of education of the subjects. The general objective was supported by the following specific objectives: to handle an object and throw an object. To achieve this, the following notional content is developed in relation to the specific objectives mentioned above. To achieve the first specific objective, the notional contents are the grip and the rolling of the cylinder with two hands. The use of both hands is explained by the good thrust to be given to the cylinder at the time of propulsion. Indeed, the cylinder must roll at a speed that does not allow the opponent to reach it easily. This requires strength and power from the upper limbs and also the correct placement of the supports. In addition, the second specific objective can only be achieved when the subject in a static position launches on a mobile cylinder in the form of translation. Throwing in translation allows the subject to better control and synchronize the members better. This is remarkable in the javelin where the throw is made in translation to better orient its center of gravity and to use with precision the stiffness of its members and to adjust the trajectory of its lance to the moving target. The task is to launch the lance on the movable cylinder. This notional content constitutes a contextualization of experiential knowledge with a view to their contextualization by experimentation as indicated by Chevalier and Takiek (2004).

Regarding the students of the first year elementary course, the general objective that we proposed is to develop the skills of locomotion and manipulation. The specific objective is to launch an object. To do this, launching a lance on a mobile cylinder after a walk constitutes the corresponding notional content. The course recommended before throwing the arrow constitutes a preparatory impulse for throwing. Indeed, when walking, there is a dynamic component of the effort that is initiated. This dynamic component generates transferable energy from the lower gear to the upper gear and therefore improves the speed of execution and the force with which the lance is launched.

As for the pupils of the elementary course second year, we propose to subject them to the learning of the TPA Ekienga in physical education to achieve the objective similar to that presented in CE1. However, the specific objective is to improve the physical qualities of the subjects. This is explained by the fact that at this level, the subjects begin to carry out activities; therefore, they must have the physical qualities used in preferential activities. For this purpose, children of peri-pubertal age (case of schoolchildren of this level of study) are characterized by the esteem of the characters and activities, while taking orientations related to the activity or to the preferred character (Tanner \&Whitehouse, 1976). Faced with this, the teaching content of these subjects must be marked by dynamism and an imposing load. This is noticeable through the following notional contents: grip of the cylinder with two hands; rolling the cylinder with one hand; throw the lance on the cylinder after a run; placement of the armed launching arm; explosive projection of the lance on the mobile cylinder. These actions improve physical qualities of coordination, skill, speed of execution, flexibility and 
balance. Indeed, coordination undoubtedly makes it possible to act with precision, without stiffness, without great energy expenditure and to adjust one's throw to the trajectory and the rolling speed of the cylinder. The speed and the force allow to reach the cylinder, therefore a ballistic adjustment; on the other hand, the balance held by the maintenance of the supports contributes to the good projection of the lance and corollary improves the performance. Therefore, the notional content of the Ekienga in CE2 class is adapted to these students in order to improve the physical qualities necessary for the practice of this activity.

With regard to CM1 and CM2 classes, the general objective set for learning Ekienga is to develop the skills of locomotion and manipulation. To reach this general objective, the specific objective formulated for the pupils of CM1, was to develop the capacities of lance, which is reached during the period of the great efforts facilitating the social integration of the man. This fact is illustrated by the sentence: "the growing child can claim to be integrated into the life of adults only after having proven by performing tasks that are beneficial to society" (Rigal, 1995, p.72). Finally, the improvement of motor actions at CM2 is dependent on the improvement of the organic and motor qualities and the individual and collective behaviors necessary for human life. Thus, learning from Ekienga helps develop skills related to autonomy, responsibility, health, safety, etc., hence the capital interest of its contextualization.

\section{Research Limitations and Delimitations}

However, the interpretation of our results must take into account the following limitations. First, the nature of the study allows only a time snapshot. A longitudinal and extensive survey in the four departments of northern Congo would have been better suited to the design of the teaching curricula of the TPA Ekienga. Second, the information on the ethnic origins of the respondents was based only on their statements, without rigorous verification. However, these limits mentioned do not completely affect the power of the observations. In any case, this study is the first in our community. This study provides an exploitable data bank in educational environment for taking into account traditional physical practices in physical education.

\section{Conclusions}

The results we have reached show that the teaching content of Ekienga, considering socio-constructivist approaches, cognitive and ecological psychology, constitutes the knowledge to be taught comprising the objectives and the notional contents. The specificity of TPA Ekienga characterized by internal logics of each allowed to build didactic frameworks always taking into account the level of the learner and the environment with the precision of the motor responses. These teaching contents make it possible to develop disciplinary and transversal skills. We got this during our first study.

\section{References}

Barbry, R. (1999). Modelisation de la differenciation pédagogique en EPS. Revue de la Recherche en Education, 33, 9-19. https://doi.org/10.3406/spira.1999.1555 


\section{Macrothink}

Caumel, J. G. (1995). L'éducation physique comme savoir de l'action motrice. Paris, France, ESF Collection Pédagogique.

Chevalier, M. (2004). Apprentissage moteur, processus d'adaptation cognivo-moteur. Notes de cours sur le site internet du professeur. Retrieved from http://www.er.uqm.cal nobel/r1211

Chevalier, M., \& Taktek, K. (2004). Apprentissage moteur de l'enfance à l'adolescence. UQAM, Montréal, Québec, Canada.

Christophel, D. (1990). The relationships anong teacher immediacy behaviors, student motivation and learning. Communication Education, 39, 323-340. https://doi.org/10.1080/ 03634529009378813

Famose, J. P. (2002). Apprentissage moteur et motivation. Conférence à l'Académie de Poitiers. Poitiers, France, Institut National de Recherche Pédagogique.

Fernandez, A. (2002). Rupture et prise d'avantage en sports collectifs, un modele théorique. In J. F. Grehaigne (Ed.), Autour du temps. Apprentissages, Espaces et Projets dans les sports collectifs. Université de Franche-Comté, France.

Fortin, J. (2000). Encyclopédie visuelle des sports. Genève, Minerva.

Hinshaw, K. E. (1983). The Effects of Mental Practice on Motor Skill Performance: Critical Evaluation and Meta-Analysis. Journal of Sport Psychology, 5, 25-57. https://doi.org/10.1123 /jsp.5.1.25

INRAP (Institut National de Recherche et d'Action Pédagogique). (2003). Livre programme de l'école primaire. Brazzaville, INRAP.

Lembe, G. (2009). Intégration des Activités Physiques Traditionnelles à l'école primaire: Décontextualisation et Contextualisation (Master thesis, Université Pédagogique Nationale, Kinshasa, D.R. Congo).

Lembe, G. (2012). Recontextualisation des Activites Physiques Traditionnelles à l'ecole primaire en République du Congo (Thèse de doctorat, Université Pédagogique Nationale, Kinshasa, République Démocratique du Congo).

Lembe, G., Ewamela, A., \& Massamba, A. (2019). Contribution of the teaching of traditional physical activities to knowledge in physical education at the primary school in Congo-Brazzaville. Am J Innov Res Appl Sci, 9(6), 425-433.

Paivo, A. (1985). Cognitive and motivation functiony in imagery in human performance. Canadian Journal of Applied Sports, 10(4), 376-95.

Pineau, C. (1990). Introduction à la didactique de l'EPS (p. 316). Paris, France, Dossier EPS.

Rigal, R. (1995). Motricité himaine: fondements et applications pédagogiques, Tome II. Développement moteur. Sainte-Foy, Québec, Presses Universitaires du Québec. 
Sackett, R. S. (1994). The influences of symbolic rechearisd upon the retention of a maze habit. Journal of General Psychology, 10, 376-98. https://doi.org/10.1080/00221309. 1934.9917742

Tanner, J. M., \& Whitehouse, R. H. (1976). Clinical longitudinal standards for height, weight velocity and stages of puberty. Arch Dis Child, 51, 170-179. https://doi.org/10.1136/adc. 51.3.170

UNESCO. (2005). Conference générale $33^{\mathrm{e}}$ session. Rapport préliminaire sur l'opportunité et la portée d'une charte internationale de jeux et sports traditionnels. Paris, France, UNESCO.

\section{Copyright Disclaimer}

Copyright for this article is retained by the author(s), with first publication rights granted to the journal.

This is an open-access article distributed under the terms and conditions of the Creative Commons Attribution license (http://creativecommons.org/licenses/by/3.0/). 